Hugo, W. B. \& Street, H. E. (1952). J. gen. Microbiol. 6, 90-94

\title{
The Effect of Phenol, 2-Phenoxyethanol and Cetyltri- methylammonium Bromide on the Oxidation of various Substrates by Escherichia coli
}

\author{
By W. B. HUGO AND H. E. STREET* \\ The University, Nottingham
}

SUMMARY: Effects of phenol, 2-phenoxyethanol and cetyltrimethylammonium bromide on the oxygen uptake of suspensions of Escherichia coli supplied with various single oxidizable substrates were examined. Phenol and 2-phenoxyethanol at low concentrations caused a stimulation of oxygen uptake in the presence of mannitol, glucose or lactose which was not associated with an increase in viable count, no stimulation with glycerol, and a retarded oxygen uptake with lactate, succinate or pyruvate. At higher concentrations phenol and 2-phenoxyethanol caused a retardation of oxygen uptake with all substrates, the degree varying with the substrate. Cetyltrimethylammonium bromide was toxic at very low concentrations and no stimulation of oxygen uptake by low concentrations or differential response in presence of different substrates was found.

Phenol, 2-phenoxyethanol (phenoxetol) and cetyltrimethylammonium bromide (cetrimide) chosen as representative of anionic, non-ionizing and cationic antiseptics respectively, were examined for their effect on respiratory mechanisms of Esch. coli as shown by the effect on oxygen uptake in presence of various substrates.

\section{EXPERIMENTAL}

Organism. The organism used was Esch. coli NCTC 5934. It was subcultured in nutrient broth, and freeze-dried (Proom \& Hemmons, 1949). Culture medium. Nutrient broth was prepared by the tryptic digestion of lean meat; after autoclaving it had a $\mathrm{pH}$ of $7 \cdot 2-7 \cdot 4$. It was solidified when required by the addition of $2 \%$ agar.

Chemicals. The 2-phenoxyethanol (phenoxetol) was supplied by Nipa Laboratories Ltd., Cardiff. The cetyltrimethylammonium bromide (cetrimide) was a commercial sample which, assayed by the method of The British Pharmaceutical Codex (1949), contained 84.4\% (w/w) of $\mathrm{C}_{19} \mathrm{H}_{33}\left(\mathrm{CH}_{3}\right)_{3} \mathrm{NBr}$. The sugars and mannitol used were of bacteriological quality as supplied by Messrs T. Kerfoot Ltd.; sodium pyruvate was prepared by the method of Robertson (1942); all other chemicals were of A.R. quality.

Phosphate buffers. $0.1 \mathrm{M}$ or $0.05 \mathrm{M}-\mathrm{KH}_{2} \mathrm{PO}_{4}$ and $\mathrm{Na}_{2} \mathrm{HPO}_{4} .12 \mathrm{H}_{2} \mathrm{O}$ were mixed immediately before use, to give a $\mathrm{pH}$ value of $7 \cdot 0$ (electrometric). Ringer's solution was prepared according to Wilson (1922) and sterilized by autoclaving; final $\mathrm{pH}$ c. $\mathbf{7 \cdot 5}$.

Bacterial suspensions. The contents of a tube of freeze-dried material were reconstituted with nutrient broth, grown at $37^{\circ}$ for $18 \mathrm{hr}$., then subcultured

* Present address : Department of Botany, University of Manchester. 
twice and inoculated on to nutrient agar. After $24 \mathrm{hr}$. at $37^{\circ}$ this slope was stored at room temperature and served as the immediate source of organism during 3-4 weeks, after which a new slope was made from another freeze-dried tube. This method yielded organisms giving reproducible results. For the preparation of suspensions, a third subculture from the agar slope, grown in $5 \mathrm{ml}$. nutrient broth for $18 \mathrm{hr}$. at $37^{\circ}$, was used to inoculate $250 \mathrm{ml}$. nutrient agar contained in a $3 \mathrm{l}$. Thomson culture bottle. This culture was incubated at $37^{\circ}$ for $48 \mathrm{hr}$., the cells washed off with the Ringer's solution, the suspension centrifuged twice and resuspended in Ringer's solution. Suspensions so prepared were standardized by means of a photoelectric nephelometer to contain $6 \cdot 2-6 \cdot 8 \mathrm{mg}$. dry weight cells $/ \mathrm{ml}$. and stored at $4^{\circ}$. Under these conditions suspensions retained their activity for at least 8 days.

Determination of oxygen uptake. The usual Warburg technique was used. Usually the main compartment of the Warburg vessel contained $1 \mathrm{ml}$. substrate $(0.02 \mathrm{M})$ in phosphate buffer $(0.05 \mathrm{M})$ and $0.5 \mathrm{ml}$. solution of the antiseptic; in side arm, $0.5 \mathrm{ml}$. bacterial suspension; in centre well $0.2 \mathrm{ml} .20 \%$ $\mathrm{NaOH}$ solution and an $18 \mathrm{~mm}$. square of folded filter paper. To study higher concentrations of the relatively insoluble phenoxetol, the main vessel contained $0.5 \mathrm{ml}$. of $0.04 \mathrm{M}$ substrate in $0.1 \mathrm{M}$ phosphate buffer and $1 \mathrm{ml}$. of antiseptic solution. The gas phase was air; all measurements were made at $37^{\circ}$ and 100 oscillations/min.

The effects of the three antiseptics on the oxidations of mannitol, glucose, lactose, glycerol, pyruvate, lactate and succinate were studied, at substrate concentration $0.01 \mathrm{~m}$ to ensure excess. With zero and low concentrations of antiseptics the relationship between time and oxygen uptake was linear, except with lactose, when the rate increased during the first $60 \mathrm{~min}$. The rate of oxidation was proportional to the volume of bacterial suspension used. In Figs. 1-4 the oxygen uptake values in presence of antiseptic are expressed as percentages of the uptake in the absence of antiseptic at the time stated. The activity of the suspensions under the conditions adopted can be judged from the following $Q_{\mathrm{O}}$, values $\left(\mu \mathrm{l} . \mathrm{O}_{2} / \mathrm{mg}\right.$. dry weight cells $/ \mathrm{hr}$.) for various substrates: succinate (114), glucose (100), lactate (88), pyruvate (82), glycerol (80), mannitol (72), lactose (48).

Viable counts. Volumes of substrate solution, antiseptic solution and cell suspension as used in the Warburg flasks were placed in $25 \mathrm{ml}$. conical flasks and incubated at $37^{\circ}$. At the end of a period of time equal to that of the corresponding Warburg experiment a $1 \mathrm{ml}$. sample was removed and diluted serially in Ringer solution to give 100-200 colonies/plate on nutrient agar. Counts were made after 3 days' incubation at $37^{\circ}$. When cetrimide was the inhibitor, the procedure was modified in that the first ml. of inoculum was placed in $9 \mathrm{ml}$. of sterile $1 \%$ Lubrol W. (Imperial Chemical Industries Ltd.), in a 1 oz. MeCartney bottle containing 18-20 glass beads ( $3 \mathrm{~mm}$. diam.), and well shaken to disperse clumped organisms before further dilution in Ringer's solution and plating (Davies, 1949). 


\section{RESULTS}

Each experiment involved a study of the time course of oxygen uptake in presence of graded doses of antiseptic and a single substrate. From these observations two types of curve were constructed: $(a)$ time-graded action curves where, for each antiseptic concentration, the oxygen uptake was plotted against time; $(b)$ dose-response curves where dose of antiseptic was plotted against volume of oxygen utilized at the end of a given period.

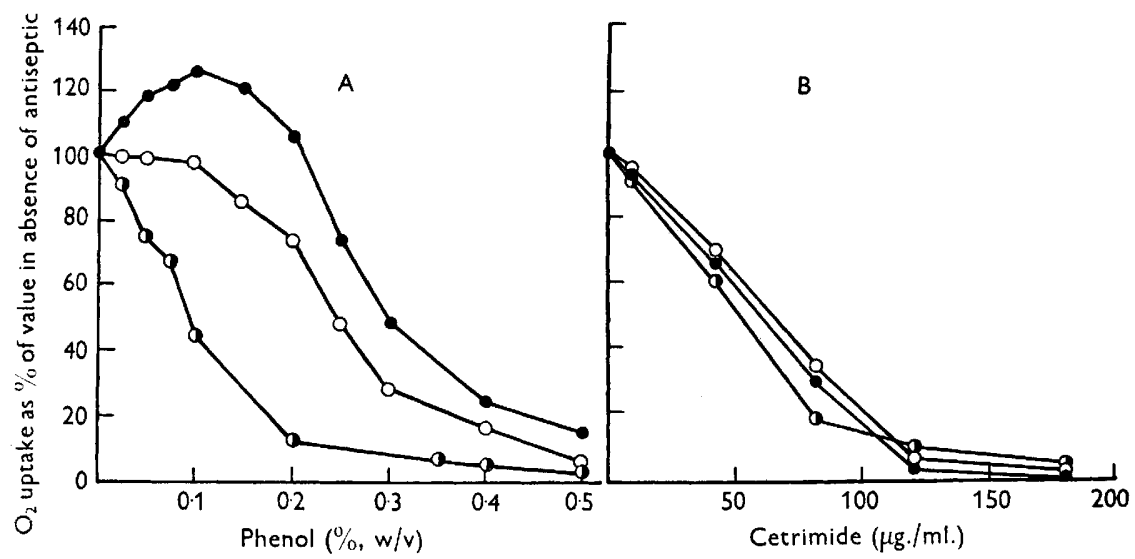

Fig. 1. Dose-response curves. Oxygen uptake in $60 \mathrm{~min}$. against various concentration of

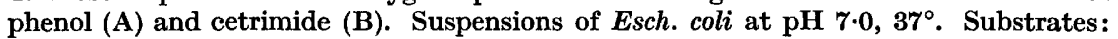
- mannitol; $\backslash-\boldsymbol{J}=$ succinate; $\mathrm{O}-\mathrm{O},=$ glycerol. Substrate concentrations $0 \cdot 01 \mathrm{M}$.

The dose-response curves with phenol and phenoxetol were of three types, according to the substrate being oxidized (an example of each type is shown in Fig. 1A). Curves obtained with mannitol, glucose or lactose as substrate. A stimulation in the rate of oxygen uptake occurred with phenol at concentrations up to $0.2 \%(\mathrm{w} / \mathrm{v})$ and with phenoxetol up to $0.3 \%(\mathrm{w} / \mathrm{v})$; the rate of oxygen uptake was increasingly depressed by the higher concentrations of antiseptic. Curves obtained with glycerol as substrate. The rate of oxygen uptake was not affected by concentrations of phenol below $0.15 \%(w / v)$ or of phenoxetol below $0.25 \%(\mathrm{w} / \mathrm{v})$, but was progressively depressed by higher concentrations. Curves obtained with succinate, lactate or pyruvate as substrate. Even the lowest concentrations tested $(0.025 \%, w / v$, for phenol and $0 \cdot 1 \%$, $\mathrm{w} / \mathrm{v}$, for phenoxetol) caused decreased oxygen uptakes, progressively more marked at higher concentrations.

With cetrimide, differences of response with different substrates were not seen and no stimulation of oxygen uptake was observed (Fig. 1B).

Stimulation or inhibition of oxygen uptake, when it occurred, was noticeable within $5 \mathrm{~min}$. of application of the antiseptic and, except at the higher concentrations, this rate which was characteristic for each substrate-antiseptic combination was maintained for the duration of the experiments. Viable counts showed no increase in the number of organisms over the stimulating 
dose range. The form of the curves relating viable count at the end of $60 \mathrm{~min}$. to dose of drug showed that there was some parallelism, with each of the three antiseptics used, between decrease in oxygen uptake with increasing dose of

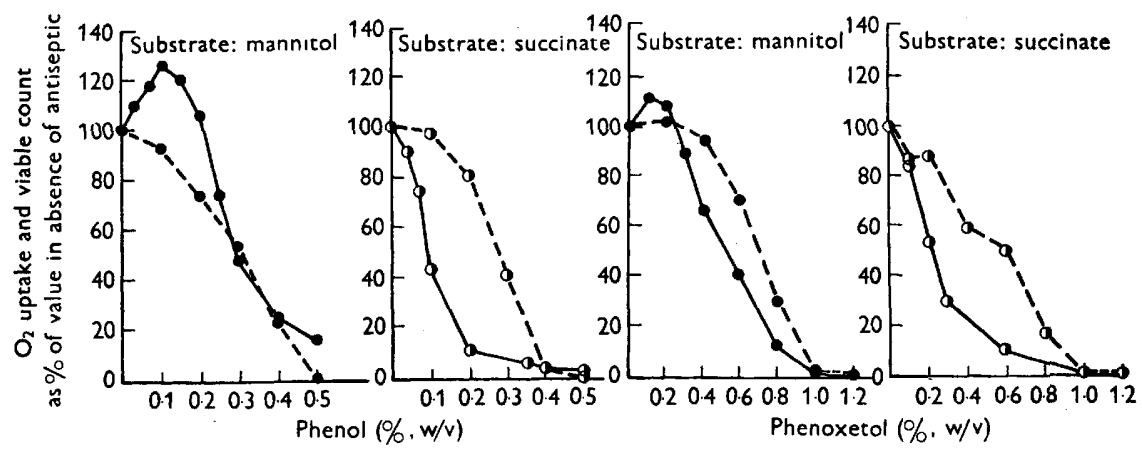

Fig. 2. Oxygen uptake in $60 \mathrm{~min}$. and viable count at end of $60 \mathrm{~min}$. at various concentrations of phenol and phenoxetol. $\mathrm{pH} 7 \cdot 0$, temp. $37^{\circ} .-$, oxygen uptake; ----, viable count.
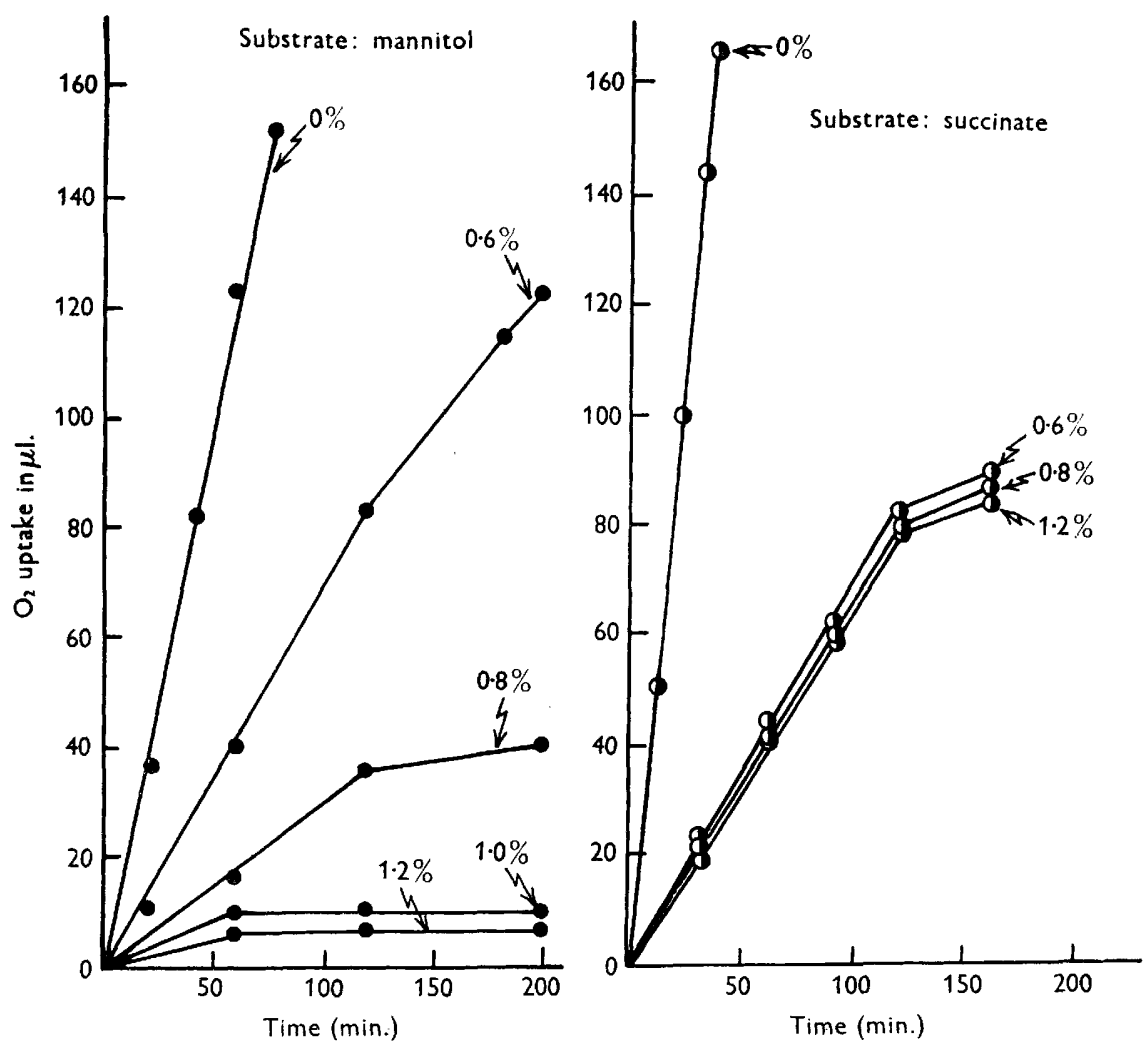

Fig. 3. Time-graded action curves showing the effect of high concentrations of phenoxetol on the course of oxygen uptake in presence of mannitol and succinate. Numbers on curves indicate $\%(\mathrm{w} / \mathrm{v})$ phenoxetol. 
antiseptic and the decrease in the viable population (results with phenol and phenoxetol are shown in Fig. 2).

The nature of the substrate modified the response to higher concentrations of phenol and phenoxetol. With mannitol and glycerol a concentration of $0.6 \%(\mathrm{w} / \mathrm{v})$ phenoxetol caused $c .70 \%$ decrease in rate of oxidation, and $\mathbf{1 . 0} \%$ phenoxetol completely abolished respiratory activity after $60 \mathrm{~min}$. (Fig. 3). With succinate and lactate there was no significant difference between the effects of 0.6 and $1.2 \%(\mathrm{w} / \mathrm{v})$ phenoxetol, during $150 \mathrm{~min}$., when a steady but very gradually decreasing oxygen uptake was observed (Fig. 3).

Antiseptics and detergents, under certain conditions promote the leakage of cell constituents from bacteria (Hotchkiss, 1946; Gale \& Taylor, 1947; Salton, $1950,1951)$ and enable sugars to enter cells more readily (Deere, 1939). Evidence has also been obtained that the enzymes concerned with the utilization of certain sugars are intracellular (Deere, 1939), whereas those concerned in the oxidation of organic acids may be at or near the cell surface (Quastel, 1926). The results obtained here with phenol and phenoxetol may be related to their effect on substrate permeability, and on access to the oxidizing enzymes.

We express our thanks to Mr G. E. Trease and Prof. C. G. C. Chesters for facilities made available in the Departments of Pharmacy and Botany.

\section{REFERENCES}

British Pharmaceutical Codex (1949), p. 232.

Davies, G. E. (1949). Quarternary ammonium compounds. A new technique for the study of their bactericidal action and the results obtained with Cetavlon (Cetyl trimethylammonium bromide). J. Hyg., Camb., 47, 271.

DeEre, C. J. (1939). On the activation of the lactase of Escherichia coli-mutabile. J. Bact. 37, 437.

Gale, E. F. \& TAYlor, E. S. (1947). The action of tyrocidin and some detergent substances in releasing amino-acids from the internal environment of Strep. faecalis. J. gen. Microbiol. $1,77$.

Hotchkiss, R. D. (1946). The nature of the bactericidal action of surface active agents. Ann. N.Y. Acad. Sci. 46, 479.

Proom, H. \& Hemmons, Lois M. (1949). The drying and preserving of bacterial cultures. J. gen. Microbiol. 3,7 .

Quastel, J. H. (1926). Dehydrogenations produced by resting bacteria. A theory of the mechanism of oxidations and reductions in vivo. Biochem. J. 20, 166.

Robertson, W. (1942). The preparation of sodium pyruvate. Science, 96, 93.

Salton, M. R. J. (1950). The bactericidal properties of certain cationic detergents. Aust. J. Sci. Res. B. 3, 45.

Salton, M. R. J. (1951). The adsorption of cetyltrimethylammonium bromide by bacteria, its action in releasing cellular constituents and its bactericidal effects. J. gen. Microbiol. 5, 391.

WiLson, G. S. (1922). The proportion of viable bacteria in young cultures with special reference to the technique employed in counting. $J$. Bact. 7, 405 . 